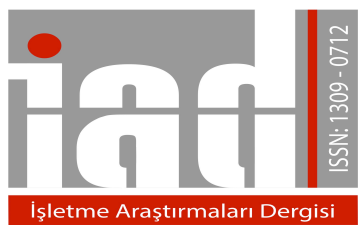

Journal Of

Business Research

Turk

www.isarder.org

\title{
Halka Açık Türk Şirketlerinin Finansal Tablolarının Uyum Düzeyi \\ Harmonization of Turkish Listed Companies' Financial Statements
}

\author{
Aydin KARAPINAR \\ Gazi Üniversitesi \\ İktisadi ve İdari Bilimler Fakültesi \\ İşletme Bölümü, Ankara, Türkiye \\ aydink@gazi.edu.tr
}

\begin{abstract}
Özet
Araştırmamız, Sermaye Piyasası Kurulu (SPK) tarafindan yayınlanan finansal tablo formatlarına şirketlerin uyum düzeyini ölçmeyi hedeflemektedir. Çalışmamız, İstanbul Borsa'sına kote 420 şirketin 2013 ve 2014 yılı bilançoları ve gelir tabloları üzerinde yürütülmüştür. Geliştirilen formül yardımı şirketlerin finansal tablolarının formata uyum derecesi hesaplanmıştır. Araştırma sonuçlarına göre, yayınlanan formatlara uyum düzeyinin oldukça yüksek olduğu, gelir tablosuna uyum düzeyinin, bilançoya uyum düzeyinin üzerinde olduğu ortaya çıkmıştır. Diğer taraftan bireysel finansal tablolardaki uyumun konsolide tablolara göre daha yüksek olduğu belirlenmiştir. Şirketlerin, formata bağlı kalarak raporlama yaptığı görülmüştür. Bu durum, Türkiye'nin kültürel yapısını ile de uyumlu çıkmıştır.
\end{abstract}

Anahtar kelimeler: Finansal tablo format1, harmonization at accounting, de facto harmonization, muhasebede kültür etkisi

\section{Abstract}

The research aims to measure the harmonization level of companies to financial statements formats that were issued by Capital Market Board (SPK). The article examines the financial statements covering periods of 2013 and 2014 of 420 companies that are publicly traded in Istanbul Capital Market. Harmonization level is calculated by a formula developed in the article. According to findings, the harmonization is so high, and the harmonization of income statements are over that of balance sheets. On the other hand, the harmonization of sole financial statements is higher than that of consolidated financial statements. It is seen that the companies comply with the formats. The findings are in aligned with the sociological structure of Turkey determined

Keywords: Financial statement format, harmonization at accounting, de facto harmonization, culture effect in accounting 


\section{Giriş}

Çıkar grubu olarak adlandırabileceğimiz, işletmeyle ilgili olanlar; çalışanlar, ortaklar, yöneticiler, müşteriler, potansiyel yatırımcılar gibi birçok farklı kesimi içermektedir. Çıkar grupları, beklentilerini karşılayacak, işletmeyle ilgili birçok farklı bilgiye ihtiyaçlar duymaktadırlar. $\mathrm{Bu}$ bilgiler ise, ilgililerin karar vermede kullanacakları, işletmelerin faaliyet sonuçları ve finansal durumuna ilişkin finansal bilgilerden oluşmaktadır. Finansal bilgi tanımına, karar vermeye yardımcı olacak her türlü bilgi girmektedir. Bu bilgilerin, şekli bir yapısı bulunmamaktadır. Bununla birlikte, finansal bilgiler, temelde, muhasebe sisteminden elde edilen bilgileri kapsamaktadır. Muhasebe sistemi ise, belirli dönemler itibariyle, işletme ile ilgili bilgilerin hazırlanıp sunulması sürecini ifade etmektedir.

Muhasebe sisteminde, finansal bilgiler, finansal tablolar aracılığıyla sunulmaktadır ve bu tablolar işletmeyle ilgili tüm grupların beklentileri karşılamaya yönelik hazırlanan, genel amaçlı finansal tablolardır. Bir başka ifadeyle finansal bilgiler temelde, muhasebe sistemi tarafindan hazırlanan finansal tabloları ifade etmektedir.

Finansal tablolar, finansal bilgi kullanıcıları için en önemli bir bilgi kaynağıdır. Karar vermede esas alınan finansal tabloların belirli özelliklere uygun olarak hazırlanması gereklidir. Finansal Raporlamaya İlişkin Kavramsal Çerçeve (KGK, 2011) bu özellikleri, "ihtiyaca uygunlukluk", "gerçeğe uygun sunuş", "karşılaştırılabilirlik", "doğrulabilirlik", "zamanlılık" ve "anlaşılabilirlik" olarak belirlemiştir.

$\mathrm{Bu}$ özelliklerden, karşılaştırılabilirlik, muhasebe uygulamalarındaki uyumla sağlanabilmektedir. Uyum, ülkedeki işletmelerin benimsediği aynı muhasebe uygulamaların ifade etmektedir(Don ve Thomas, 1995). Aynı muhasebe politikalarının kullanılması uyumu arttırmakta, aksi ise düşürmektedir.

Uyum, yasal uyum (de jure or formal) ve maddi uyum olarak (de facto or material) ikiye ayrılmaktadır. Uyumun yasal düzenlemeler tarafından sağlanması, birinci uyumu, uygulamada ortaya çıkması ise ikinci uyumu ifade eder (Emenyonu ve Adhikari, 1998). Sebebi ne olursa olsun, uyum, sunum (disclosure) uyumu ve değerleme (measurement) uyumu olarak ortaya çıkmaktadır (Canibano ve Mora, 2000).

Çalışmamızda, SPK tarafından yayınlanan finansal tablo formatlarına halka açık şirketlerin uyum düzeyi araştırılacaktır. SPK tarafından yayınlanan tablolara uyum bir zorunluluk değildir. Bu bakımdan araştıracağımız uyum düzeyi maddi uyum düzeyi olacaktır. Araştırmamız, KGK (Kamu Gözetimi Muhasebe ve Denetim Standartları Kurumu) açıklamalarının bir zorunluluk algısı yaratmasından yola çıkmaktadır. Ülkemizdeki muhasebe kültürünün de bu sürece etki edeceği düşünülmektedir.

Çalışmamızın diğer bir amacı, formata uyumun ölçülmesine ilişkin bir yöntem geliştirmektir. Araştırmada, uyum kendi geliştirdiğimiz yöntemle ölçülmeye çalışılacaktır.

Çalışmamızda öncelikle, finansal tablo uygulama rehberi çerçevesinde finansal tablo uyum zorunluluğu incelenecek, daha sonra, Literatür taraması yapılacaktır. Araştırma metodolojisi ve bulguları ayrı bölümler halinde ele alınacaktır. En son olarak tartışma ve sonuç bölümlerine yer verilecektir. 


\section{Finansal Tablolara İlişkin Düzenlemeler}

Türkiye Muhasebe Standartları (TMS/TFRS), finansal tabloların şekli yapısının belirlendiği bir format öngörmemektedir. Standartta, finansal tablolar ve dipnotlarda "gerçeğe uygun sunuluşu" sağlamak amacıyla, bir raporlama formatından ve yaklaşımından kaçınılmıştır (Örten ve diğerleri, 2015). Sadece, bilanço (finansal durum tablosu) (TMS 1 Madde 54) ve gelir tablosunda (kapsamlı gelir tablosu) (TMS 1 Madde 82) asgari olarak raporlanacak kalemler belirlenmiștir. Standart, kapsamında bulunan her bir tablo için bir format veya model önermek yerine, işletmenin finansal yapısı ve performasına ilişkin bilgilerin anlaşılır ve karşılaştırılabilir sunuluşunu amaçlamaktadır.

Ülke uygulamalarına bakıldığında, Uluslararası Muhasebe Standartlarının uygulanmasında, finansal tablolara ilişkin bir format oluşturulmadığı görülmektedir. Ülkelerin kendi yerel mevzuatlarında ise, iki uygulamayla karşılaşılmaktadır. Bunlardan birincisi, sadece finansal tablolara ilişkin bir formatın belirlenmesi, diğeri ise format yanında detaylı hesap planının oluşturulmasıdır (Lapteş and Sofian, 2014). Kıta Avrupası ülkeleri (Almanya Fransa, İspanya gibi), hesap planı bazlı uygulamayı benimserken, Anglo-Sakson ülkeler (İngiltere, İrlanda, Hollanda gibi), finansal tablo formatı bazlı formatı benimsemektedirler (Lapteş ve Sofian, 2014).

Ülkemizde muhasebe uygulamaları, Almanya ve Fransa ekollerinden büyük ölçüde etkilenmiştir (Orten ve Bayirli, 2007). Hesap planı da muhasebe uygulamamızın temelini oluşturmaktadır. Ülkemizde, 1992 yılında Maliye Bakanlığı tarafından yayınlanan Muhasebe Sistemi Uygulama Genel Tebliği (1992) ile tekdüzen hesap planı, 20 yılı aşkın bir süredir uygulanmaktadır.

SPK, 2003 yılında itibaren, borsaya kote şirketlerin finansal tablolarının Uluslararası Muhasebe Standartlarına göre düzenlenmesi esasına getirmiştir. Ancak, standartlar yönünde önemli adımlar, Türk Ticaret Kanunu (TTK) değişikliği ile atılmıştır. TTK, KGK'yi, değişik şirket büyüklükleri, sektörler ve kâr amacı gütmeyen kuruluşlar için özel ve istisnai standartlar koymaya ve farklı düzenlemeler yapmaya yetkili kılmıştır (TTK 88. Madde). KGK bu yetkiye istinaden, halka açık şirketlerin finansal tablolarının Uluslararası Muhasebe Standartları ile uyumlu Türkiye Muhasebe Standartlarına göre düzenlenmesi esasını benimsemiştir. KGK (2013), 2013 yılında "Finansal Tablo Örnekleri ve Kullanım Rehberi" adlı Kurul İlke Kararını yayınlayarak, finansal tablolara ilişkin düzenlemeler yapmıştır.

SPK (SPK, 2013), KGK tarafından yayımlanan "Finansal Tablo Örnekleri ve Kulanım Rehberi”ni esas alınarak, sermaye piyasası ihtiyaçlarını da göz önünde bulundurularak, kamuya ilan edilecek finansal rapor formatlarında yer alması gerekli asgari unsurları belirlemiştir. Yayınlanan formatlar, 31.03.2013 tarihinden sonra sona eren ara dönemlerden itibaren yürürlüğe konulmuştur.

KGK yayınladığı rehberin amacını aşağıdaki gibi ifade etmiştir (KGK, 2013).

“...finansal tablolarını Türkiye Muhasebe Standartlarına (TMS) göre düzenlemek zorunda olan şirketlerin finansal tablolar aracilığıyla ilgililere sunduğu bilgilerin gerçeğe ve ihtiyaca uygunluğunu, karşılaştırılabilirliğini, doğrulanabilirliğini ve anlaşılabilirliğini arttırmak, finansal tablolarının yeknesak olmasını sağlamak ve denetimini kolaylaştırmak amacıyla hazırlanması..." 
Kurum, temel amaç olarak, TMS 1'de yer alan finansal bilgilerin özellikleri saymış, yeknesaklığı sağlama ve denetimi kolaylaştırma amaçlarını bunlara ilave etmiştir. Yine aynı düzenlemede, rehberin, TMS/TFRS kapsamında, şirketlerin yapması gereken tüm sunum ve açıklama hükümlerini kapsamadığı, uygulama birliği sağlamayı ve yönlendirici olmayı amaçladığı da belirtilmiştir. Oysaki muhasebe standartları, finansal tabloların amacını, geniş bir kullanıcı kitlesinin ekonomik kararlar almalarına yardımcı olan işletmenin finansal durumu, finansal performansı ve nakit akışları hakkında bilgi sağlamak olarak açıklamaktadır (TMS 1 madde 9).

KGK (KGK, 2013) rehberde, formatın amacını aşağıdaki gibi ifade etmiştir.

“..TMS'yi uygulamakla yükümlü olan şirketlerin hazırlayacakları finansal tablolara örnek teşkil eder.”

KGK bu hükümle, formatın bir zorunluluk olmadığını, sadece örnek teşkil ettiğini ifade etmiştir.

Görüldüğü gibi, TMS 1'de sadece bilanço ve gelir tablosu için açıklanması gereki asgari kalemlere yer verilmesine rağmen KGK ve SPK detaylı finansal tablolar düzenlemiştir. Düzenlenen bu tabloların örnek niteliğinde olduğu ise açıkca belirtilmiştir.

\section{Literatür Taraması}

Literatürdeki çalışmaların bazıları, yasal uyumu (Rahman ve diğerleri, 1996), çoğunluğu ise maddi uyumu (Van der Tas, 1988, 1992; Walton, 1994; Emenyonu ve Gray, 1992; Archer ve diğerleri, 1995; Pierce ve Weetman, 2000; Karapınar, 2001; Zaif, 2013) araştırmışlardır. Araştırmaların ortak yanı, değerleme uyumu üzerine yoğunlaşmış olmalarıdır (Canibano ve Mora, 2000). Sunum uyumu üzerine yapılan tek çalışma, Karapınar ve Zaif (2008) tarafından yürütülmüştür.

Emenyonu and Gray (1992), Almanya, Fransa ve İngiltere muhasebe uygulamalarını esas alarak yürüttüğü çalışmada, büyük farklığı, geniş ancak nispeten düşük aralıklı uyumu tespit etmiştir. Van der Tas (1992), 15 avrupa ülkesinde 150 halka açık şirketi incelemiş, hem konsolide hem de bireysel tabloları esas almış ve değerleme ve açıklamalar bağlamında uyumu değerlendirmiştir. Araştırma sonuçları konsolide ve bireysel tablo ayrımı olmadan uyum konusunda büyük farklılıklar olduğunu belirlemiştir.

Archer ve diğerleri (1995) uyumu ülke içi ve ülkeler arası ayrı ayrı ele almıştır. Elde ettiği sonuçlara göre, ülke içi uyum, ülkeler arası uyuma göre daha yüksek çıkmıştır. Herrmann ve Thomas (1995), 8 Avrupa Birliği ülkesinden 217 şirketinin uyum düzeyini 9 değerleme ilkeleri üzerinden incelemiştir. Araştırma sonuçları, varlık ve borçların yabancı paraya çevrilmesinde, yabancı para çevrim farklarında ve stokların değerlemesinde yüksek, duran varlıkların değerlemesinde, amortismanlarda, şerefiyede, araştırma ve geliştirme diğerlerinde, stokların maliyetlendirilmesinde, gelir ve giderlerin yabancı paraya çevrilmesinde düşük uyum düzeyi olduğu ortaya koymuştur.

Karapınar (2001) Türkiye'nin en büyük 500 sanayi şirketi üzerinde yaptığ çalışmada, halka kapalı şirketlerin uyum düzeyinin, halka açık şirketlerden daha yüksek olduğunu saptamıştır. Çalışmanın diğer önemli bir bulgusu, halka açık şirketlerin uluslararası uyum düzeyinin ise halka kapalı şirketlerden daha yüksek olduğunu 
göstermektedir. $\mathrm{Bu}$ sonuç, tekdüzen muhasebe sisteminin yeknesaklık konusunda başarılı olduğunun bir göstergesi olarak nitelendirilmiştir.

Zaif (2013), İstanbul Menkul Kiymetler Borsasına kote grup şirketler üzerinde bir araştırma yapmış ve denetim şirketlerinin bu şirketlerin uyum düzeyine etkileri araştırmıştır. Araştırma sonuçları, denetim şirketlerinin, borsaya kote grup şirketlerin uyum düzeyini arttırdığını göstermiştir.

Karapınar ve Zaif (2008), halka açık 27 şirketin gelir tablosunu incelemiş ve SPK tarafından yayınlanan uyumunu ortaya koymaya çalışmıştır. Çalışmanın sonuçları, 6 şirketin tablo formatına tam uyum gösterdiğini, uyumsuzluk alanlarının ise temelde, finansman giderlerinin, reeskont gelir ve giderlerinin, özkaynak yöntemiyle değerlenen yatırımlardan payların raporlanması konusunda olduğunu ortaya koymuştur. Karapınar ve Zaif (2008) araştırma sonuçlarına göre, tekdüzen hesap planı etkilerinin devam ettiği sonucuna varmışlardır.

\section{Araştırma Metodolojisi}

Araştırma İstanbul Borsasında işlem gören şirketler üzerinde yürütülmüştür. İnceleme dönemi itibariyle halka açı şirket sayısı 516'dir. Bu şirketlerden, finans şirketleri incelemeye dahil edilmemiştir. Geriye kalan 420 şirketin tümü inceleme kapsamına alınmıştır.

Tablo 1: İncelenen Şirketlerin Kapsamı

\begin{tabular}{lc}
\hline & $2014-2013$ \\
\hline Halka Açık Şirketler & 516 \\
(-) Bankalar & 22 \\
(-) Faktoring Şirketleri & 33 \\
(-) Finansal Kiralama Şirketleri & 12 \\
(-) Fonlar & 13 \\
(-) Varlık Kiralama Şirketleri & 10 \\
(-) Diğer Finans Kuruluşlar & 6 \\
\hline İncelemeye Dahil Şirketler & 420 \\
\hline
\end{tabular}

Her şirketin 2013 ve 2014 yılı sonu itibariyle biten döneme ait bilanço ve gelir tablosu (dönem karı veya zararı tablosu) incelemeye konu edilmiştir. Kapsamlı gelir tablosu, nakit akım tablosu ve özkaynaklar değişim tablosu incelenmemiştir. Sadece, bilanço ve gelir tablosununun incelenmesinin nedeni, bu tabloların tekdüzen hesap planı tarafından temel tablo olarak belirlenmiş olması ve şirketlerin öteden beri devam eden formata uyum alışkanlıklarıdır. Diğer taraftan amacımızın, uyumu ölçmeye yönelik bir yöntem geliştirilmesi olması nedeniyle, veri kapsamının genişletilmesi gerekli görülmemiştir.

Finansal tablo formatı olarak, borsaya kote şirketlerin esas aldığı SPK tarafından yayınlanan finansal tablo formatları esas alınmıştır. Finansal tablolarda yer alan her kalem tek tek incelenmiş, yazım yanlışları ve benzer anlamı ifade eden kalemler uyumlu kabul edilmiştir.

Yayınlanan finansal tabloların formata uyum oranı geliştirdiğimiz aşağıdaki formül yardımı ile hesaplanmıştır. 


$$
\begin{aligned}
& \sum_{i=1}^{n} \frac{1-\frac{p_{i}}{f s}}{n} \\
& n=\text { şirket sayısı } \\
& p_{i}=i \text { şirketinin uyumsuz finansal tablo kalemi } \\
& \text { fs }=\text { finansal tablo kalemi sayısı }
\end{aligned}
$$

Formüle göre, her bir şirketin finansal tablosunda yer alan ancak, SPK tarafindan yayınlanmayan her bir kalem tespit edilmiş ve bu kalemin formattaki kalem sayısına bölünmesi suretiyle uyumsuzluk yüzdesi bulunmuştur. Bu yüzde birden çıkarılarak her bir şirketin uyum oranı hesaplanmıştır. Uyum oranları toplanarak, şirket sayısına bölünmüş ve uyum ortalama oranı bulunmuştur.

Aynı hesaplama, her bilançoda her bir ana grup içinde uygulanmıştır. Baz olarak her bir gruptaki kalemler esas alınmıştır. Ana gruplardaki uyum oranın hesaplanmışında ise aşağıdaki formül kullanılmıştır.

$$
\begin{aligned}
& \sum_{i=1}^{n} \frac{1-\frac{p g_{i}}{f g s}}{n} \\
& \mathrm{n}=\text { şirket sayısı } \\
& \operatorname{pg}_{\mathrm{i}}=\mathrm{i} \text { şirketinin ilgili hesap grubunda yer alan uyumsuz finansal tablo kalemi } \\
& \mathrm{fgs}=\text { finansal tablo grubunda yer alan kalemi sayısı }
\end{aligned}
$$

\section{Bulgular}

İnceleme sonuçları her yıl için ayrı ayrı ortaya konmuştur. Uyum düzeyi finansal tabloların tümü için hesaplandığ 1 gibi, her bir tablo için de ayrı ayrı hesaplanmıştır. İncelenen dönemde, en yüksek ve en düşük uyum düzeyine sahip şirket veya şirketlerin uyum düzeyleri raporlanmıştır. Uyum, konsolide ve bireysel finansal tablolara göre ayrıştırılmıştır. Uyum düzeyi yayında SPK formatından farklılaşan finansal tablo kalemleri sayı olarak da hesaplanmış ve minimum, maksimum düzeyleri, genel ortalama ve konsolide ve bireysel tablo ortalamaları ortaya konmuştur.

Tablo 2: 2013 yılı uyum oranları

\begin{tabular}{lcccccc}
\hline & \multicolumn{2}{c}{ Bilanço } & \multicolumn{2}{c}{ Gelir Tablosu } & \multicolumn{2}{c}{ Genel } \\
\hline & $\%$ & Say1 & $\%$ & Say1 & $\%$ & Say1 \\
\hline Max & $98 \%$ & 2 & $100 \%$ & 0 & $97 \%$ & 3 \\
Min & $78 \%$ & 22 & $35 \%$ & 13 & $79 \%$ & 25 \\
Ort & $89 \%$ & 11 & $96 \%$ & 1 & $90 \%$ & 12 \\
Birey. & $91 \%$ & 9 & $97 \%$ & 1 & $92 \%$ & 10 \\
Kon. & $88 \%$ & 12 & $96 \%$ & 1 & $89 \%$ & 13 \\
\hline
\end{tabular}


Tablo 3: 2014 yılı uyum oranları

\begin{tabular}{lcccccc}
\hline & \multicolumn{2}{c}{ Bilanço } & \multicolumn{2}{c}{ Gelir Tablosu } & \multicolumn{2}{c}{ Genel } \\
\hline & $\%$ & Say1 & $\%$ & Say1 & $\%$ & Say1 \\
\hline Max & $98 \%$ & 2 & $100 \%$ & 0 & $98 \%$ & 2 \\
Min & $78 \%$ & 22 & $50 \%$ & 10 & $81 \%$ & 23 \\
Ort & $89 \%$ & 11 & $96 \%$ & 1 & $90 \%$ & 12 \\
Birey. & $91 \%$ & 9 & $97 \%$ & 1 & $92 \%$ & 10 \\
Kon. & $88 \%$ & 12 & $96 \%$ & 1 & $89 \%$ & 13 \\
\hline
\end{tabular}

Bilanço uyum düzeyi daha detaylı olarak ele alınmıştır. Her bir ana grup itibariyle uyum düzeyleri hesaplanmıştır. Hesaplamada konsolide ve bireysel tablo ayrımı yapılmıştır.

Tablo 4: 2013 yılı bilanço uyum oranları

\begin{tabular}{lcccccccccc}
\hline & \multicolumn{1}{c}{ Dön.Var. } & \multicolumn{2}{c}{ Dur.Var. } & \multicolumn{2}{c}{ KVKY } & \multicolumn{2}{c}{ UVK } & \multicolumn{2}{c}{ Özk. } \\
\hline & $\%$ & Say1 & $\%$ & Say1 & $\%$ & Say1 & $\%$ & Say1 & $\%$ & Say1 \\
\hline Maks & $100 \%$ & 0 & $100 \%$ & 0 & $95 \%$ & 1 & $100 \%$ & 0 & $100 \%$ & 0 \\
Min & $61 \%$ & 7 & $67 \%$ & 7 & $52 \%$ & 10 & $80 \%$ & 4 & $67 \%$ & 6 \\
Ort & $88 \%$ & 2 & $88 \%$ & 2 & $74 \%$ & 5 & $95 \%$ & 1 & $96 \%$ & 1 \\
Birey. & $89 \%$ & 2 & $90 \%$ & 2 & $77 \%$ & 5 & $97 \%$ & 1 & $97 \%$ & 1 \\
Kon. & $87 \%$ & 2 & $87 \%$ & 3 & $72 \%$ & 6 & $94 \%$ & 1 & $95 \%$ & 1 \\
\hline
\end{tabular}

Tablo 5: 2014 yılı bilanço uyum oranları

\begin{tabular}{lcccccccccc}
\hline & \multicolumn{2}{c}{$\begin{array}{c}\text { Dönen } \\
\text { Varlk }\end{array}$} & \multicolumn{2}{c}{$\begin{array}{c}\text { Duran } \\
\text { Varlıklar }\end{array}$} & \multicolumn{2}{c}{ KVK } & \multicolumn{2}{c}{ UVK } & \multicolumn{2}{c}{ Özkaynak } \\
& $\%$ & Say1 & $\%$ & Say1 & $\%$ & Say1 & $\%$ & Say1 & $\%$ & Say1 \\
\hline Maks & $100 \%$ & 0 & $100 \%$ & 0 & $95 \%$ & 1 & $100 \%$ & 0 & $100 \%$ & 0 \\
Min & $61 \%$ & 7 & $71 \%$ & 6 & $52 \%$ & 10 & $80 \%$ & 4 & $67 \%$ & 6 \\
Ort & $88 \%$ & 2 & $88 \%$ & 2 & $74 \%$ & 5 & $95 \%$ & 1 & $96 \%$ & 1 \\
Birey. & $89 \%$ & 2 & $90 \%$ & 2 & $77 \%$ & 5 & $96 \%$ & 1 & $97 \%$ & 1 \\
Kon. & $87 \%$ & 2 & $87 \%$ & 3 & $72 \%$ & 6 & $94 \%$ & 1 & $95 \%$ & 1 \\
\hline
\end{tabular}

\section{Tartışma}

Araştırma sonuçları, her iki finansal tablo birlikte düşünüldüğünde uyum düzeyinin yaklaşık \%90 olduğunu göstermektedir. Bu oran dönemler arasında bir farklılık sergilememektedir. Yüksek uyum düzeyi şirketlerin büyük bir çoğunlukla SPK formatını esas aldıkları göstermektedir. $\mathrm{Bu}$ oran, bireysel tablolarda \% 92'ye çıkmaktadır. Bu sonuç, bireysel tablolarda, konsolide tablolara göre daha yüksek uyum olduğunu ifade etmektedir.

Minumum ve maksimum oranlara bakıldığında, \% 100 bir uyum düzeyi olmamakla birlikte, 2013 yılında \% 97, 2014 yılında \% 98 uyum görülmektedir. Minumum uyum düzeyi ise \% 79'dan, \% 80'e çıkmıştır. Maksimum uyum gösteren şirket/şirketler ile minumum uyum gösteren şirketler arasıda fark 2013 yılında \% 18, 2014 yilında ise, \% 17'dir.

Finansal tablolar düzeyinde uyum incelendiğinde, gelir tablosunun ortalama uyum düzeyi $\% 96$, bilançonun uyum düzeyi ise \% 89 olup, yıllar arası değişim 
göstermemiştir. Gelir tablosundaki uyum düzeyinin, bilanço uyum düzeyinin ortalama bazda daha yüksek olduğu ortaya çıkmaktadır. Konsolide ve bireysel tablolarda, gelir tablosu uyum düzeyi, bilanço uyum düzeyinden yüksektir. Burada çarpıcı bir sonuç, gelir tablosunun genel anlamda uyum düzeyi yüksek olmakta birlikte, maksimum ve minumum uyum düzeyleri arasındaki fark, bilançoya göre daha yüksek çıkmaktadır. 2013 y1lında gelir tablosunda fark \% 65 (\% 100-\%35), bilançoda \% 20'dir (\% 98-\% 78). 2014 yılında farklar sırasıyla, \% 50 ve \% 20 olarak gerçekleşmiştir. Gelir tablosunda \% 100 uyum düzeyine sahip şirket/şirketler bulunmaktadır. Ancak, uyum düzeyi \% 35 olan şirket/şirketler da bulunmaktadır. 2014 yılında, minumum ve maksimum uyum düzeyleri birbirlerine yaklaşsalar bile, bilanço uyum düzeyleri arasındaki farkla mukayese edilemez niteliktedir. Bu sonuçlar, bazı şirketlerin farklı ihtiyaçları gereği formatlardan uzaklaşabildiğini, ancak bunun ortalamayı çok büyük oranda etkilemeyecek kadar az şirkette olduğunu göstermektedir.

Gelir tablosunda maksimum farklı kalem sayısı, bir önceki yıla göre, 13'den 10'a düşmüştür. Bilançoda ise yıllar arasında bir farklılık gözlemlenmemektedir. Ortalamada ise gelir tablosunda farklı kalem sayısı 1, bilançoda 11'dir. En çok farklılaşmaya neden olan gelir tablosu kalemi "finansman gelirleri" dir. 280 şirket, "finansman gelirleri" kalemini formattan farklı olarak açmışlardır. Formatta, TMS 1'e de uygun olarak sadece "finansman giderleri" kalemi yer almakta, finansman gelirleri, finansman giderleri içinde düşünülmektedir.

Bilançoda en çok farklılaşmaya neden olan kalem "Ortak Kontrole Tabi Teşebbüs veya İşletmeleri İçeren Birleşmelerin Etkisi” dir. Bu kalem, 2014 yılında 24, 2013 yılında ise 21 şirket tarafından açılmıştır. Bu kalemin, birleşme sonucu zorunlu olarak ortaya çıkmasına rağmen formatta uygun bir kalemle ilişkilendirilememesi, şirketleri ayrı bir hesap açmaya yönlendirmiş gibi görülmektedir.

İkinci en sık açılan finansal tablo hesabı, "diğer yedekler"dir. Diğer yedekler, 2014 yılında 13, 2013 yılında 15 şirket tarafından açılmıştır. Formatta, sadece "Kardan Ayrılmış Kısıtlanmış Yedekler" kaleminin yer alması, ancak kısıtlanmamış yedekler için bir kalem öngörülmemiş olması, şirketleri yeni bir hesap açmaya itmiş gibi anlaşılmaktadır.

Bilançonun ana grupları itibariye uyum düzeyi incelendiğinde, yıllar itibariyle uyum düzeylerinde bir değişiklik meydana gelmemiştir. Her ana grup bazında bireysel bilançolarda uyum, konsolidelere göre daha yüksek çıkmaktadır En yüksek uyum düzeyi \%96 ile özkaynaklarda sağlanmıştır. En düşük uyum düzeyi ise kısa vadeli yabancı kaynaklarda görülmektedir. Ayrıca, en düşük ve en yüksek uyum düzeyi farkı \% 43 ile yine kısa vadeli yabancı kaynaklarda meydana gelmiştir. Sayı olarak da, formata göre en çok farklı hesap bu grupta açılmıştır. Uzun vadeli yabancı kaynaklarda uyum düzeyi, \% 95 olup, özkaynaklardan sadece \% 1 düşük olmasına rağmen, özkaynaklardan farklı olarak maksimumum ile minumum uyum düzeyleri arasındaki fark en az olan ana grup olarak çıkmaktadır. Bu durum, özkaynak işlemlerinin, UVYK işlemlerine göre daha fazla türde işlemleri içermesi olarak yorumlanabilir.

Diğer yandan, finansal tablo formatlarına yüksek uyumun bir diğer nedeni de, formatların çok detaylı olarak düzenlenmiş olmasıdır. Formatlar, TMS 1 hükümlerinde açıklanan asgari finansal tablo kalemlerinin oldukça üstünde finansal tablo kalemini kapsamına almaktadır. Bu durum, şirketlerin ayrı hesap açma ihtiyaçlarının azaltan bir etmen olarak ortaya çıkmaktadır. Nitelik, TMS 1 hükümlerine göre (TMS 1 madde 54), 
özkaynaklar içinde iki hesap grubunun açıklanması yeterli görülmüşken, SPK formatında 17 finansal tablo kalemi yer almaktadır. Araştırma sonuçlarımızda en yüksek uyumun özkaynaklarda çıkması bu tespitimizi doğrulamaktadır.

Araştırma sonuçları, Karapınar ve Zaif (2008) tarafından yürütülen araştırma sonuçları ile tutarlıdır. Sadece gelir tablosu hesapları alınarak yapılan araştırmada, şirketlerin \% 22'sinin SPK formatına tam uyum gösterdiği, hatta kendilerinde olmayan kalemleri dahi formatta oldukları için raporladıklarını ortaya koymuştur. Araştırmamız, Karapınar ve Zaif tarafından 2008 yılında yapılan araştırmadan bu yana, formata bağımlılığın devam ettiğini göstermektedir.

Yasal düzenlemelere bağlılığın nedenlerinin ortaya konması yararlı olacaktır. Muhasebe uygulamalarının tarihsel olarak ülkeler arasında farklılık gösterdiği (Nobes, 2002, Bloom,1997) ve muhasebenin bir ülke kültürünün önemli bir fonksiyonu olduğu tartışılmaktadır (Leonard ve diğerleri, 2010). Türk muhasebe uygulamaların tarihsel olarak sırasıyla Fransa ve Almanya etkisinde kalmıştır. Kıta Avrupası grubunda yer alan bu ülkelerin temel özelliği olan hesap planı uygulaması da ülkemizin kültürel bir özelliği haline gelmiştir. 1960'lardan sonra Amerika etkileri görülmesine ve son yıllarda yaşanan Uluslararası Standartlara geçiş çabalarına rağmen, kültürel kökler, finansal tablo formatına bağl1lığın sürdürüldügünü göstermektedir.

Hofstede (1980, Askary ve diğerlerinden naklen, 2008) Türkiye'nin sosyokültürel değerleri hakkında araştırma yapmış ve Türkiye'yi bireysellik ve erkeksilik özellikleri zayıf, belirsizlikten kaçınma ve güç mesafesi güçlü bir ülke olarak tasnif etmiştir. Belirsizlik kaçınma ve güç mesafesinin göreceli olarak düşük olması, toplumun yasal kontrol odaklı bir toplum olduğunun bir göstergesi olarak görülmektedir (Askary ve diğerleri, 2008). Gray (1988), Hofsede'nin (1980) kültürel ayrımını, uluslararası muhasebe farklıklarını açıklamak üzere kullanmıştır. Türkiye'nin dahil olduğu grubu, muhasebe sistemi açısından, yasal kontrol odaklı ve yeknesaklığı yüksek olarak tasnif etmiştir.

Askary ve diğerlerinin (2008) Türkiye'de muhasebe uygulamalarında kültürel değerlerin etkileri üzerine bir araştırma yürütmüştür. Araştırma sonucunda, yüksek güç mesafesi ve belirsizlikten kaçınma ile düşük bireyselliğin, muhasebe yeknesaklığ arasında pozitif bir bağ olduğu ortaya konmuştur. Araştırma sonuçlarımız, gerek Hofstede (1980) ve gerekse Askary ve diğerlerinin (2008) yaptığ 1 çalışmaların sonuçlarını desteklemektedir. Muhasebe alanında, otoriteye uyma alışkanlığının devam ettiğini ve bu durumunda yeknesaklığı ortaya çıkardığını görmekteyiz. Bu durum, KGK tarafından altı çizilen, "raporlarda yeknesaklık" beklentisinin gerçekleştiğini göstermektedir.

KGK ve SPK gibi düzenleyici otoritelerin, düzenleme yaparken, bu kültürel etkiyi gözönünde bulundurmaları yararlı olacaktır. Açıklama ve yorum niteliğinde yapılan bir düzenlemenin bile, bir zorunluluk gibi algılanması, TMS/TFRS'lerin gerçeğe uygun sunuluşu felsefesinden şirketleri uzaklaştırıcı bir etken olarak ortaya çıkabilecektir. Bu durum bir sonraki adımı zorunlu kılacak ve daha detaylı ve bağlayıcı düzenlemeler yapılması zorunlu hale gelecektir. Kurum (KGK, 2015), "Kur Farklarının Borçlanma Maliyeti Olarak Aktifleştirilmesi”" adlı bir taslak ilke kararı yayınlaması da bu yöndeki gidişin bir göstergesi olarak yorumlanabilir. 


\section{Sonuç}

Çalışmamız, SPK tarafından yayınlanan finansal tablo formatlarına halka açık şirketlerin maddi uyum düzeyini, sunum uyumu üzerinden ölçmeyi hedeflemektedir. Araştırma borsaya kote 230 şirket üzerinde yürütülmüştür. Uluslarası muhasebe standartlarına uygun ilk tabloların düzenlendiği yıl olan 2013 yılı ve sonraki yıl olan 2014 y1lı incelemeye konu edilmiştir. Araştırma tarihi itibariyle henüz 2015 tabloları yayınlanmadığı için, 2015 yılı tabloları araştırmaya dahil edilmemiştir.

Araştırma sonuçları aşağıdaki başlıklar altında toplanabilir:

- Yayınlanan formatlara uyum oldukça yüksektir.

- Gelir tablosu uyum düzeyi, bilanço uyum düzeyinin üzerindedir.

- Özkaynak grubunda uyum düzeyi, diğer finansal tablo gruplarına göre daha yüksektir.

- Bilançoda en düşük uyum düzeyi kısa vadeli yabancı kaynaklarda görülmektedir.

- Bireysel finansal tabloların uyum düzeyi, konsolide finansal tablolardan daha yüksektir.

- Yıllar arasında uyum düzeylerinde önemli değişiklik görülmemiştir.

Elde edilen sonuçlar, Türkiye'nin kültürel kodları ile uyumlu olarak değerlendirilmiştir. Türkiye'nin sosyolojik olarak yasal kontrol odaklı toplum niteliği, muhasebe alanında da kendini göstermektedir. Sonuçlar, düzenleyici otoritelerin finansal tablolarda yeknesaklığı sağlama hedefine ulaştığını ifade etmektedir. Ancak, düzenleyici otoritelerin, bu kültürel kodları gözönünde bulundurarak hareket etmeleri yararlı olacaktır. Aksi durumda, TMS/TFRS'lerin temel ruhunda uzaklaşma, her şeyin düzenlenmesi ve açıklanması gibi bir durumla karşı karşıya kalınabilecektir.

Araştırmada sadece bilaço ve gelir tablosu inceleme konusu yapılmıştır. Kapsamlı gelir tablosu, nakit akım tablosu ve özkaynak değişim tablosu incelenmemiştir. Sözkonusu tablolara uyum başka çalışmalara konu edilebilir.

\section{Kaynakça}

Archer, S., Delvaille, P.,McLeay, S., (1995). "The measurement of harmonisation and the comparability of financial statement items: within-country and between country efects", Accounting and Business Research, Vol. 25, No.98, 6780.

Archer, S., Delvaille, P., McLeay S., (1995). "The Measurement of Harmonization and the Comparability of Financial Statement Items: Within-- Country and BetweenCountry Effects", Accounting and Business Research, Vol. 25, No.98, 67-80

Askary, S., Yazdifar, H., Askarany, D., (2008). "Culture and accounting practices in Turkey", International Journal of Accounting. Auditing and Performance Evaluation, Vol.5, No.1, 66-88.

Bloom, R., (1997). "International accounting controversies", The Government Accountants Journal, Vol. 46, No. 3, 58-59. 
Canibano, L., Mora A.,(2000). "Evaluating the statistical significance of de facto accounting harmonization: a study of European global players", The European Accounting Review, Vol. 9, No. 3, 349-369.

Don H., Thomas W., (1995). "Harmonization of Accounting Measurement Practice in the European Committee", Accounting and Business Research, Vol. 25, No.100, 254-270.

Emenyonu, E. N., Gray, S. J., (1992). "EC accounting harmonisation: an empirical study of measurement practices in France, Germany and UK", Accounting and Business Research, Vol. 23, No. 89, 4958.

Emenyonu, E.. N., Adhikari A., (1998). "Measuring the Degree of International Harmony in Selected Accounting Measurement Practices", Australian Accounting Review, Vol. 8, No. 2, 24-32

Gray, S. J.,(1988). "Towards a theory of cultural influence on the development of accounting systems internationally", Abacus, Vol. 24, 1-15

Herrmann, D., Thomas W., (1995). "Harmonization of Accounting Measurement Practices in the European Community", Accounting and Business Research, Vol. 25, No. 100, 253-265

Kamu Gözetimi Muhasebe ve Deneim Standartları Kurumu, (2015). erişim http://www.kgk.gov.tr/contents/files/taslak_\%20ilke\%20karari.pdf, erişim tarih: 30.04.2016

Kamu Gözetimi Muhasebe ve Denetim Standartları Kurumu, (2011) "Finansal Raporlamaya İlişkin Kavramsal Çerçeve", erişim http://www.kgk.gov.tr/contents/ files/TFRS_2013/F_R_I_K_C(1).pdf,erişim tarihi: 01.02.2016

Kamu Gözetimi Muhasebe ve Denetim Standartları Kurumu, (2013). erişim http://www.kgk.gov.tr/contents/files/TMS_Ilke_Kararlari/Ilke_Karari_1.pdf, erişim tarihi: 01.02.2016

Karapınar, A., Zaif F., (2008). "SPK Düzenlemeleri Açısından Gelir Tablosunda Yer Alan Bilgilerin Sunumu ve İMKB'de Bir İnceleme”, Muhasebe Bilim Dünyası Dergisi, Vol. 2008, No. 2, 25-54

Karapınar, A., (2001). "Ülkemiz Muhasebe Politikaları Açısından Ulusal ve Uluslararası Uyumu", Muhasebe Bilim Dünyası Dergisi, Vol. 3, No. 1, 95-110

Lapteş, R., Sofian, I., (2014). "Convergences and Divergence Between Financial Reporting Systems of Romania and Spain", Bulletin of the Transilvania University of Braşov, Vol. 7, No. 56, 207-218

Leonard K. M., Slaubaugh, M., Wang, H.C., (2010). "Cultural effects on accounting practices and investment decisions", International Journal of Accounting and Finance, Vol. 2, No. 2, 156-170. doi: 10.1504/IJAF.2010.032086

Maliye Bakanlığı, (2012). Muhasebe Sistemi Uygulama Genel Tebliğ. T.C. Resmi Gazete, 21447, 26.12.2012.

Nobes, C.W. (Ed.)., (2000). GAAP 2000: a survey of national accounting rules in 53 countries. Monograph by Arthur Andersen, BDO, Deloitte Touche Tohmatus, Ernst \& Young International, Grant Thornton, KPMG, and 
PricewaterhouseCoopers. Retrieved from www.iasplus.com/resource/gaap2000. pdf.

Orten, R., Bayirli, R., (2007). "Development of Accounting and Accounting Profession in Turkey in Second Half of 20th Century", Paper presented at the 5th Accounting History International Conference, Banff, Canada, 9-11 August.

Pierce, A., Weetman, P., (2000) "The impact of non-disclosure on measurement of de facto harmonisation: a two country comparison", Paper presented at the 23rd Annual Congress of the European Accounting Association, Munich.

Rahman, A., Perera, H., Ganeshanandam, S., (1996) "Measurement of formal harmonisation in accounting: an exploratory study", Accounting and Business Research, Vol. 26, No. 4, 32539.

Sermaye Piyasası Kurulu, (2013). Kurul İlke Kararı, 07.06.2013 tarih ve 20/670 sayıl1 Karar, erişim http://www.spk.gov.tr/displayfile.aspx?action=displayfile\&pageid= 925\&fn=925.pdf

Van der Tas, L. G., (1988). "Measuring harmonisation of financial reporting practice", Accounting and Business Research, Vol. 18, No. 70, 15769.

Van der Tas, L.G., (1992). "Evidence of European Community Financial Reporting Practice Harmonization: The Case of Deferred Taxation", The European Accounting Review, Vol. 1, No. 1, 59-104.

Walton, P., (1992). "Harmonizationof accountingin France and Britain: some evidence", Abacus, Vol. 28, No. 2, 18699.

Zaif, F., (2013). "The effects of audit firms and parent companies on material harmonization: a perspective of Turkey", World of Accounting Science, Vol. 15, No. 1, 1-28. 


\title{
Harmonization of Turkish Listed Companies' Financial Statements
}

\author{
Aydin KARAPINAR \\ Gazi University \\ Faculty of Economics and Administration Sciences \\ Business Administrative Department, Ankara, Turkey \\ aydink@gazi.edu.tr
}

\section{Extensive Summary}

\section{Introduction}

Financial statements are vital data sources for financial data users. Being utilized as the core resource in a decision-making process, it is a requirement to devise financial statements in accordance with certain specifications. Conceptual Framework for Financial Reporting (KGK, 2011) listed these certain specifications as being relevance, faithful representation, comparability, verifiability, timeliness, and understandability.

Among such specifications, comparability can be secured through the harmonization in accounting practices. Harmonization refers to analogous accounting practices adopted by national companies (Don and Thomas, 1995). Application of analogous accounting policies boosts harmonization while there is a decrease in harmonization if that cannot be ensured.

Harmonization is classified as formal harmonization (de jure) and material harmonization (de facto). Securing harmonization via legislative regulations stands for the first harmonization step while the emergence of harmonization in practice stage stands for the second harmonization step (Emenyonu and Adhikari, 1998). Regardless of its cause harmonization reveals itself as disclosure harmonization and measurement harmonization (Canibano and Mora, 2000).

In this paper, harmonization level of public companies with financial statements formats issued by SPK (Capital Market Board of Turkey) is examined. Harmonization with the financial statements formats is not mandated. Hence this kind of harmonization level is only related to material harmonization level.

Another objective of our study is to develop a method applicable to measure the harmonization with the financial statements formats. In this study, harmonization will be attempted to get measured via a method we developed.

\section{Method}

The research has been conducted over companies listed in Istanbul Stock Market. As of the research period, the number of public companies is 516. Among these companies finance companies have been excluded from the research. Of the remaining 420 companies, all have been included in the research.

Each company's end-of-2013 \& 2014 year balance sheet and income statements (profit or loss statement for the financial year) have been included within the scope of research. Comprehensive income statements, cash flow statements, and statements of change in equity have not been analyzed. The reason for analyzing profit or loss statements solely is because these statements were identified as the key statement by Uniform Accounting Code and companies are accustomed to complying with this long- 
established formats. On the other hand, expanding the scope of data seemed redundant since our main objective was to develop a method to measure harmonization only.

the financial statements format issued by SPK is the key foundation for this analysis. Each item in financial statements was individually analyzed; items with spelling mistakes and expressing identical meanings were labeled as harmonious.

Of the issued financial statements, the ratio of harmonization with the formats was computed via below-given formula.

$$
\begin{aligned}
& \sum_{i=1}^{n} \frac{1-\frac{p_{i}}{f_{s}}}{n} \\
& \mathrm{n}=\text { number of companies } \\
& \mathrm{pi}=\text { disharmonious financial statement item of company } \mathrm{i} \\
& \mathrm{fs}=\text { frequency of financial statement items }
\end{aligned}
$$

\section{Findings and Discussion}

Findings of our analysis have been respectively listed for each year. Harmonization level was computed for the complete set of financial statements as well as for each individual statement individually. With respect to the analyzed period, compliance of the company (or companies) with the maximum and minimum harmonization level has been reported. Harmonization has been distinguished as consolidated and individual financial statements. Financial statement items that exhibited a distinctive harmonization level with the financial statements formats issued by SPK while issued were also measured in terms of quantity to delineate minimum \& maximum levels; general average and average ratios of the consolidated $\&$ individual statement.

As seen in research findings, once the two financial statements are co-evaluated, harmonization level equates to circa $90 \%$. This ratio manifests the presence of analogy between periods. The presence of high-harmonization level proves that the high number of companies have followed the SPK formats. The same ratio escalates to $92 \%$ in individual statements. As detected there is a significantly higher level of harmonization in individual statements when compared to consolidated statements.

As harmonization in financial statements level is analyzed it is detected that average harmonization level income statements are $96 \%$, harmonization level of balance-sheet is $89 \%$, and there has been no change in different years. It surfaces that harmonization level of income statements is, on an average base, above harmonization level of balance-sheet. Among consolidated \& individual statements, harmonization level of income statements is higher than harmonization level of balance-sheet. One noticeable finding here is that although harmonization level of income statements is generically higher, difference between maximum \& minimum harmonization levels is higher than balance-sheet. In 2013 difference in income statements was 65\% (100\%$35 \%)$, and $20 \%(98 \%-78 \%)$ in balance-sheet. In 2014 differences were respectively $50 \%$ and $20 \%$. There is not any company/companies having $100 \%$ harmonization level in income statements. Also, some company/companies have $35 \%$ harmonization level. In 2014 although minimum and maximum harmonization levels got closer, they are yet not to be comparable with the difference in balance-sheet harmonization levels. These 
findings manifest that although certain companies tend to forsake the formats due to their divergent needs, this incidence was evident in relatively few companies that would not immensely affect the average ratio.

As the harmonization level is analyzed as per main groups of balance-sheet, no shifts were observed in harmonization levels throughout different years. On the basis of each main group, harmonization in individual balance-sheets is higher than consolidated ones. Maximum harmonization level $(96 \%)$ was measured in equities, and minimum harmonization level was observed in short-term liabilities. Additionally, difference between the minimum and maximum harmonization level $(43 \%)$ was also observed in short-term liabilities. As regards quantity, the maximum number of different accounts was also opened in this group. In long-term liabilities, harmonization level was $95 \%$ and although there was merely $1 \%$ fall from the equities, unlike equities, it emerges as the key group with the lowest range of difference between maximum and minimum harmonization levels. This finding can be viewed as evidencing that compared to longterm liabilities transactions equity transactions integrate further divergent transaction types.

Aside from that one reason behind the strong harmonization with the financial statement formats is that the formats were devised in minute details. The formats include financial statement items significantly above minimum financial statement items that were specified in TMS 1 provisions. This reality surfaces as one factor diminishing the needs of companies to open individual accounts. As per TMS 1 provisions (TMS 1 par.54), quality is sufficient enough to open two individual account groups in equities while in the formats 17 financial statement items are listed. This deduction is verified by the findings of our research in which maximum harmonization was measured in equities.

Findings of our research are consistent with the findings of the study conducted by Karapınar and Zaif (2008). In their study focusing singly on income statement accounts, it was identified that $22 \%$ of companies fully harmonized with the formats, and they even reported items that were nonexistent in their system just because they were listed in the formats. Our study verifies that compliance with the formats continues as of 2008- dated study of Karapinar and Zaif.

It would be of use to illuminate the reasons behind compliance with legal regulations. It has long been argued that accounting practices historically diverged among different states (Nobes, 2002; Bloom,1997) and that accounting was a crucial function of any national culture (Leonard et al., 2010). Traditionally Turkish accounting practices were steered by France and Germany. Accounts chart application as the common trait of Continental Europe States has since then become a cultural aspect of Turkey. Despite the surge of American effects as of the 1960s and recent attempts to fulfill International Accounting Standards, cultural roots still demonstrate compliance with the financial statement formats.

Hofstede (1980 cited in Askary et al., 2008) conducted studies on Turkey's sociocultural values and classified Turkey as a state with poor individuality and masculinity traits; with a higher disposition to avoid the ambiguity and with a strong power distance. Relatively low ratios in disposition to avoid the ambiguity and power distance are viewed as indicators of any legal-control focused society (Askary et al., 2008). Gray (1988) utilized Hofsede's (1980) cultural differentiation to illustrate international 
accounting differences. The scholar categorized the group Turkey belonged to as representing a strongly-uniformed and legal-control focused accounting system.

Askary et al. (2008) employed a research on the effects of cultural values on accounting practices in Turkey. The research concluded the evidence of positive correlation between high power distance \& avoidance from ambiguity and low individuality \& uniformed accounting. Findings of our research likewise echo the results of Hofstede (1980) and also Askary et al. (2008) studies. We have testified that in the field of accounting submission to authority is a continued habit, which inevitably gives rise to the emergence of uniformity. This finding demonstrates that "uniformity in reports" expectation underpinned by KGK (Public Oversight Board) has been truly actualized.

In the supervision process, it would be of use for regulatory authorities viz. KGK and SPK to take this cultural effect into account. Perceiving any regulation issued as information and comment purposes only as a mandate may emerge as one factor distancing companies from the philosophy of realistic disclosure of TMS /TFRS (Turkish Accounting Standards/Turkish Financial Reporting Standards). This misperception would inevitably enforce the consecutive step and require the enforcement of further comprehensive and binding regulations.

\section{Results}

Our study aimed to measure material harmonization level of public companies with the financial statement formats issued by SPK on the basis of disclosure harmonization. Collected results can be listed as below:

- There is a significantly high level of harmonization with the formats.

- Harmonization level of income statements is significantly above harmonization level of balance-sheet.

- In equity group, harmonization level is significantly above of all the other financial statement groups. liabilities.

- In balance-sheet minimum harmonization, level is measured in short-term

- Harmonization level of individual financial statements is significantly above consolidated financial statements.

- Not any significant changes were detected in harmonization levels among different years.

Obtained findings are deemed to be consistent with cultural codes of Turkey. Social characteristics of Turkey as a legal-control focused society can be detected in the field of accounting too. These results validate that regulatory authorities have reached their aim of ensuring uniformity in financial statements. Nevertheless, it would be for the benefit of regulatory authorities to take action by following such cultural codes. Otherwise, they would be disposed to depart from the core spirit of TMS/TFRS and feel mandated to regulate and annotate all details.

Our study mainly focused on balance sheets and income statements. Comprehensive income statements, cash flow statements and statements of chance in equity have not been analyzed. 